\title{
Urban Regeneration between Cultural Heritage Preservation and Revitalization: Experiences with a Decision Support Tool in Eastern Germany
}

\author{
Robert Knippschild ${ }^{1,2, *(1)}$ and Constanze Zöllter ${ }^{1}$ \\ 1 Leibniz Institute of Ecological Urban and Regional Development, 01217 Dresden, Germany; c.zoellter@ioer.de \\ 2 International Institute (IHI) Zittau, Technische Universität Dresden, 01069 Dresden, Germany \\ * Correspondence: r.knippschild@ioer.de
}

check for updates

Citation: Knippschild, R.; Zöllter, C. Urban Regeneration between Cultural Heritage Preservation and Revitalization: Experiences with a Decision Support Tool in Eastern Germany. Land 2021, 10, 547. https:/ / doi.org/10.3390/land10060547

Academic Editors: Katarzyna

Fagiewicz, Damian Łowicki and Ulrich Walz

Received: 14 April 2021

Accepted: 12 May 2021

Published: 21 May 2021

Publisher's Note: MDPI stays neutral with regard to jurisdictional claims in published maps and institutional affiliations.

Copyright: (C) 2021 by the authors. Licensee MDPI, Basel, Switzerland. This article is an open access article distributed under the terms and conditions of the Creative Commons Attribution (CC BY) license (https:// creativecommons.org/licenses/by/ $4.0 /)$.

\begin{abstract}
Concentrated urban development in capital cities is associated with negative effects. Simultaneously, less favourably located cities suffer from population loss and economic decline. Shrinking cities face a loss of urban functions such as public infrastructure, high-quality services and various aspects of urban living; the cultural heritage is also degraded through declining population and vacant buildings. The end result is a lower level of attractiveness and competitiveness along with negative development prospects. At the same time, booming cities and city regions face negative agglomeration externalities such as rising real estate prices and rents, traffic congestion, land use conflicts or poor environmental quality. One such shrunk town is Görlitz in Eastern Germany, where a new decision support tool to foster urban regeneration and heritage preservation has been testedthe Urban Transformation Matrix. This tool aims at revitalising the historic building stock protected by heritage preservation law. The idea is to openly discuss structural alterations to buildings in order to foster revitalisation and high-quality occupancy not only in the case of individual buildings, but also in the wider neighbourhood context, which in turn can promote further revitalisation and revaluation of the entire urban district. The Matrix takes into account both heritage aspects and the proposed post-refurbishment function of a building before launching the approval procedure for the construction work. Based on scientific monitoring, the article reflects the heated discussions around the Urban Transformation Matrix and the test-period of its application, as well as factors of successful implementation.
\end{abstract}

Keywords: urban transformation; small and medium-sized towns; revitalisation; decision support tool; cultural heritage preservation

\section{Introduction: Assumptions on Peripheralisation, Urban Transformation and Cultural Heritage}

This article addresses the conflict between cultural heritage preservation and urban regeneration, which is of particular relevance in the case study city of Görlitz in southeastern Germany. Tackling this conflict requires collaborative decision-making. We explain and discuss the approach of the Urban Transformation Matrix as an innovative decision support tool that has been tested over the last three years. The guiding question within this discussion is how an innovative decision support tool can be used to bring listed, vacant buildings into use and thus revitalise urban districts and cities. The underlying assumption is that while the revitalisation of historic city centres is a challenge in many European cities, it is also central to achieving sustainable urban transformation.

\subsection{Peripheralisation of Small and Medium-Sized European Cities}

Capital cities in the European Union play a crucial role in economic development: They are hubs for employment and competitiveness as well as drivers of innovation and growth. A comparison of the economic performance of cities in EU member states indicates 
increasing disparities in urban growth patterns. In some cases, capital cities develop into 'magnets for growth', i.e., attracting the majority of investments and resources [1]. At the same time, population decline in peripheral towns and cities ('shrinking cities') is an increasing international phenomenon and one dimension of significant socio-spatial inequalities in Europe [2-4]. Kühn describes the peripheralisation of cities as a process that goes beyond the understanding of the periphery as a mere locational disadvantage. In addition to quantifiable outward migration and infrastructural disadvantages, which are often attributed to peripheral regions, peripheralisation as a process also considers the relationship between centres and peripheries, the social production of peripheries and the unequal distribution of power in space [5]. Thus, in addition to objective criteria of locational quality, the subjective aspects of urban quality of life and the image and self-attribution of a city influence its degree of peripheralisation.

\subsection{Urban Transformation: A Prerequisite for Sustainable Development}

Concentrated urban development in capital cities or other rapidly developing urban areas is associated with negative effects like negative agglomeration externalities as rising real estate prices and rents, traffic congestion, land use conflicts and poor environmental quality $[6,7]$. On the other hand, less favourably located cities suffer from population loss and economic decline. Shrinking cities face a loss of urban functions such as public infrastructure, high-quality services and various aspects of urban living; the cultural heritage is also degraded through declining population and vacant buildings. The result is a lower level of attractiveness and competitiveness along with negative development prospects $[8,9]$.

Inequalities in spatial dynamics are associated with social polarisation and economic imbalance. Therefore, sustainable urban and regional development requires innovative solutions to cope with urban shrinkage and urban congestion. One crucial question in this context is whether small- and medium-sized cities can benefit from the problems of growing and congested cities, thereby contributing to a more-balanced spatial development.

The ongoing process of digitalisation may serve to revitalise small- and mediumsized cities by allowing more people to work from home or at non-fixed locations-a practice that has been applied intensively during the current COVID-19 pandemic. In any case, soft locational factors will become more important for settlement decisions. Such decisions will be increasingly influenced by desirable living environments and less by mere prospects of employment. In this context, many small- and medium-sized cities might gain attractiveness by offering less competitive housing and real estate markets as well as better living environments [10-12]. Certainly, this is not the case for all small- and medium-sized cities, yet those with a historic urban fabric, good environmental quality, a robust social and cultural infrastructure and lively civil society could enjoy a renaissance, even in peripheral locations.

\subsection{Cultural Heritage: Potential or Burden?}

Among such soft factors, cultural heritage can be viewed as a particular asset of small and medium-sized cities, which often face stagnation or population decline and yet have significant stocks of historic buildings. The cultural heritage in small- and medium-sized cities bears a high potential for economic, social and environmental development and is a key factor for sustainable development $[13,14]$. It can enrich the cultural diversity, foster social cohesion at a regional level and depict touristic potential.

However, in a difficult demographic context, cultural heritage can also be a burden for urban development. This applies in particular to places with vacant but culturally valuable building fabric. In many cases, traditional urban functions are additionally contested by new urban developments such as the construction of shopping malls or modern city districts on the fringes of the old town or beyond. Such circumstances pose a risk to the preservation of the built heritage in historic cities. Therefore, many of them have already lost significant historic fabric. Historic cities are, moreover, prone to losing their traditional 
service and supply functions for the city itself and for its hinterland. These processes add to the negative image and self-perception of individual towns and entire regions, which in turn aggravates the described dynamics [15].

\subsection{Collaborative Decision Support Tools for Sustainable Urban Regeneration}

A preliminary conclusion is that the revitalisation of a historic built environment is a complex and conflict-laden issue. In particular, the article highlights the dearth of research on the intersection between preservation and urban transformation. An interesting approach is the multi-attribute value theory, which is a multicriteria decision analysis (MCDA) applied in heritage protection. This methodology allows for comparing historic buildings using different criteria and facilitating stakeholders making decisions under limited financial resources [16]. In addition, the life cycle approach is promising for restoration of cultural heritage and sustainable rehabilitation. The life cycle approach basically looks at the inputs (materials, energy consumption, etc.) and outputs (emissions, waste, etc.) of a product during its life time. While the approach is already applied in construction, there is no corresponding approach in heritage conservation yet [17].

A further assumption is that soft locational factors gain importance at a time of digital transformation. Among such soft factors, built cultural heritage might be a particular asset of small and medium-sized towns, which often face stagnation or population decline and yet have significant stocks of historic buildings [15]. One of these cities is Görlitz, where a new collaborative decision support tool for sustainable urban regeneration has been tested. This Matrix as an informal instrument can contribute to solution finding. It is a starting point for an exchange between investors, architects, planners and local authorities regarding development possibilities for the historic building stock. This joint work with different stakeholders promotes understanding and points out new perspectives, which is the basis for communicatively and jointly developed new approaches to solutions [18].

\section{Case and Methodology}

\subsection{The Dilemma of Revitalisation and Heritage Preservation: The Case of Görlitz}

In this chapter, the article will take a closer look at the German town of Görlitz, which is enjoying moderate economic growth after a long period of population decline. With around 55,000 inhabitants, Görlitz is a medium-sized city with an outstanding ensemble of historic urban structures from both the Renaissance and Baroque periods as well as from the Gründerzeit (neighbourhoods in Wilhelminian style from the late 19th/early 20th century). The historic building stock of 4000 listed monuments under heritage protection is unique in Germany.

The town is located in the eastern corner of Saxony. After World War II, with the shift of the German-Polish border to the Oder-Neisse line, Görlitz was split into two separately administered halves. Subsequently, the eastern part of Görlitz became the autonomous Polish town of Zgorzelec. Görlitz suffers from its peripheral location. Access to Germany's core metropolitan areas is poor, and the hinterland on the Polish side, due to continuing (non-physical) border barriers, is not fully developed.

Furthermore, the city has been afflicted by severe demographic and socioeconomic problems for more than 25 years. Following German Reunification in 1990, and in particular in the wake of the currency reform, many businesses quickly went bankrupt or were shut down. This resulted in massive job losses that, until today, have still not been compensated. A knock-on effect of the job losses was a shrinking population, which fell by around $25 \%$ due to out-migration and a significant fall in the birth rate [19].

This population decline has been accompanied by an increasing proportion of vacant buildings, including the historic building stock. Görlitz had already been afflicted by vacancies in the town centre before 1989, when the GDR authorities constructed prefabricated housing estates in the outskirts as a remedy for derelict and virtually uninhabitable housing in historic areas. 
Despite population decline, around $75 \%$ of the historic building stock has been restored over the last 25 years, encouraging an influx of inhabitants to the town centre. One reason for this was the possibilities of tax depreciation for modernisation measures as well as several federal and state subsidy programmes. However, the vacancy rate remains high in the building stock that has not been modernised yet (see Figure 1). Many such buildings have been vacant for more than 25 years, resulting in severe damage that, in some cases, has weakened their structural stability (see Figure 2). Although little of the historic building stock has been lost, there is urgent need for action in order to preserve the unique cultural heritage in the town of Görlitz.

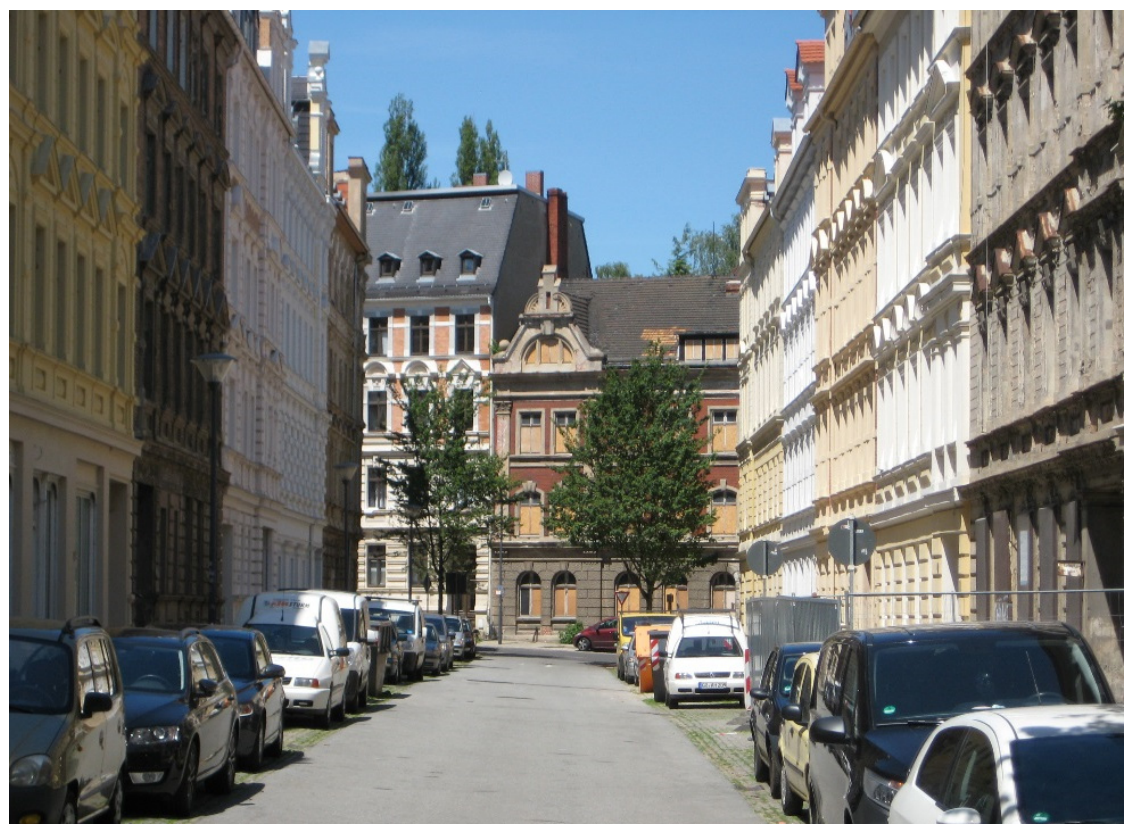

Figure 1. Renovated and un-renovated, vacant buildings in in the immediate vicinity.

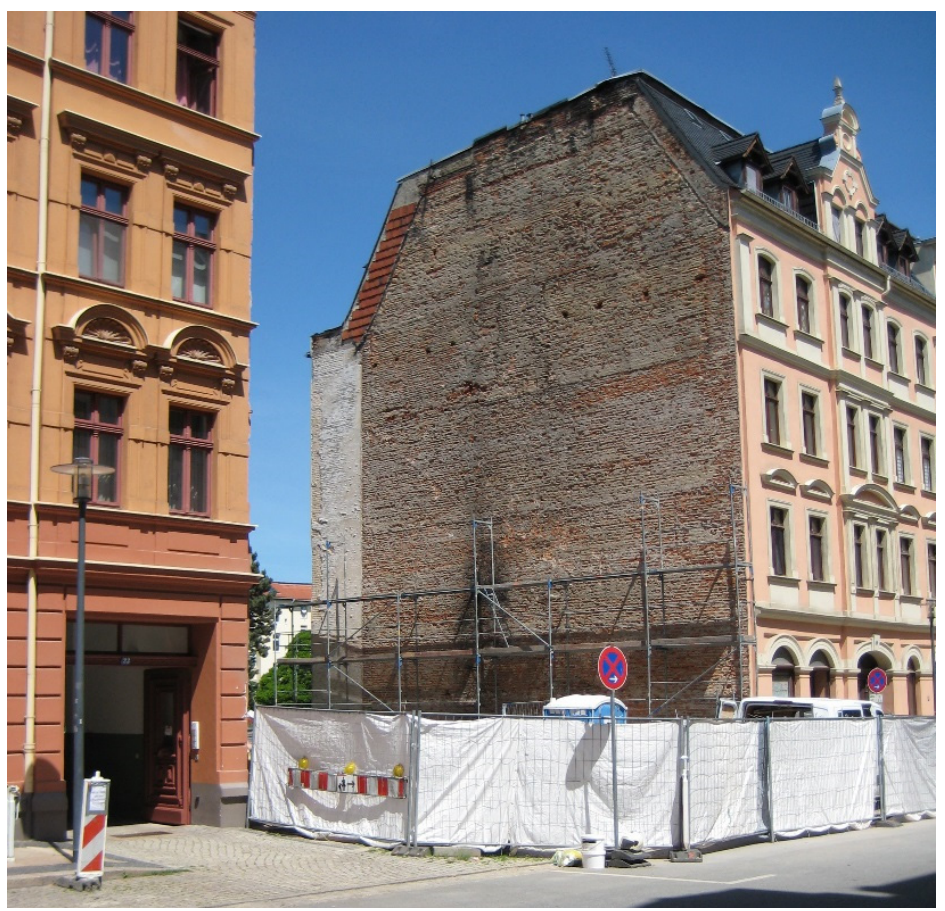

Figure 2. Vacant plot after collapse of a listed building. 
Today, the town receives much attention nationwide, both for positive and negative urban features and developments. On the one hand, Görlitz is known for its historic centre ("the most beautiful town in Germany"), for the border location and its cooperation with the Polish partner city of Zgorzelec ("Europastadt/Europamiasto") as well as for being a location for many international film productions ("Görliwood", [20]). On the other hand, it is still associated with the negative impacts of its peripheral location, namely out-migration, population decline, economic weakness and poor economic prospects.

However, the real estate and housing market in Görlitz is currently enjoying something of a boom due to growing demand for high quality housing as well as for retail outlets in central locations. This trend is certainly supported by the low lending rates of recent years in Germany and throughout Europe, encouraging investors to look for land and property beyond the core metropolitan areas, where investment options are becoming rare. Three interrelated factors-population decline, economic distress and vacant buildings-remain an urgent threat to a vast array of urban historic buildings, not only in Görlitz, but also in many other declining cities (also known as legacy, shrinking or post-industrial cities). Here, preservation orders apply to a wide range of city neighbourhoods where the private sector is willing to invest [21].

Furthermore, families and young people are "rediscovering" medium-sized towns. Again, this trend is due to the negative impacts of rapid urban expansion in metropolitan areas such as skyrocketing housing prices, increased pollution and traffic congestion. The beneficiaries are cities with attractive housing markets from a tenant's perspective and a strong social infrastructure as well as lively and unique urban lifestyles [22].

These developments provide Görlitz with the opportunity to attract residents and to overcome the challenges of population decline and vacant buildings by revitalising the historic building stock. After facing population decline for over three decades, the city has experienced stabilisation of population figures with even some modest growth for the past few years. The city is confronted with a dilemma, though: Despite its (potential) attractiveness, the enormous number of 4000 individual monuments listed under the strictest protection orders are increasingly proving to be a burden to new investments and contemporary urban developments.

In 1990, many historic buildings, in particular from the Gründerzeit period, were in a poor state of repair and threatened by demolition. In order to save them, most were quickly put under heritage preservation. Since time was short, the easiest way was to protect them as individual monuments, even though the listing of building ensembles would have been more appropriate. Such individual listing is the strictest form of heritage preservation, ensuring that virtually no changes can be made to the building, even if only a single element is the object of the heritage preservation order.

Despite demand for renovated flats as well as retail outlets in the town centre, this specific situation is increasingly constraining revitalisation in Görlitz because investors are reluctant to purchase listed historic properties, even if favourable depreciation opportunities let investors search for monuments. Indeed, the Matrix is not well-known among architects, planners or investors, and the city is doing little to raise awareness of it. This often results in the withdrawal of the investment initiative.

Görlitz is not alone in facing these complex challenges. Many other peripherally located, medium-sized cities with significant historic building stock in Germany and Europe face similar problems in adapting their listed building stock to current and future challenges.

\subsection{Methodology: Scientific Monitoring and Support}

The decision support tool was developed by the municipal office for urban development in Görlitz. Scientific consultation only began with the application of the Matrix. The Interdisciplinary Centre for Ecological and Revitalising Urban Transformation (IZS) in Görlitz, a joint research unit of the Leibniz Institute of Ecological Urban and Regional Development and the Technische Universität Dresden, has intensively accompanied this application phase. 
Scientific monitoring and support included document analyses and content analyses as well as qualitative interviews with experts. Furthermore, exchange between science and practice has been organized within a conference and public discussions on the topic of the Matrix. In general, the reception among practitioners and scientists as well as the residents of Görlitz has been highly positive.

\section{3. 'Urban Transformation Matrix' as a Decision Support Tool}

\subsection{Aims of the Tool}

The decision support tool for sustainable and inclusive urban regeneration discussed here is the 'Urban Transformation Matrix'. This tool aims at revitalising the historic building stock protected under heritage preservation law. The first aim of the tool is to preserve the historic building stock and the urban fabric of the town centre as far as possible, thereby avoiding urban "perforation", i.e., the dissolution of urban structures through demographic decline and urban sprawl, a phenomenon affecting other eastern German cities with a similar set of development conditions. This helps to preserve and enhance the attractiveness and competitiveness of the city by improving certain soft locational factors.

The second aim of the tool is to exploit current trends in the housing and property market. The idea is to openly discuss structural alterations to buildings in order to foster revitalisation and high quality occupancy not only in the case of individual buildings, but also in the wider neighbourhood context, which in turn can promote further revitalisation and revaluation of the entire urban district.

\subsection{How It Works}

The Matrix takes into account both heritage aspects and the proposed post-refurbishment function of a building before launching the approval procedure for the construction work. The innovative element is that this multi-criteria evaluation Matrix considers the planned occupancy of the modernised building and its expected impact on the urban surroundings. It should be noted that the Matrix does not affect the legal procedure for acquiring a building permit. Rather, the approach is aimed at facilitating informal communication between the private sector (i.e., the architects, planners, developers and investors) and the public sector (i.e., local authorities for urban development and the preservation of monuments) before conflicts arise in this complex field or indeed, before the investors lose interest.

The Urban Transformation Matrix takes the following four aspects into consideration (with underlying categories indicated in brackets):

1. Building typology (small row house, big row house, detached house) and year of construction;

2. Urban design evaluation (building condition, complement neighbourhood structures, landmark function or source of place identity);

3. Assessment of the planned project (architectural quality, local traditions in building construction);

4. Forecast of urban impact (impact on urban development, function as a role-model for other developments).

The significance of these factors varies according to three spatial categories, derived from a pre-existing zoning system (see Figure 3 ). The three zones indicate the degree of urban consolidation:

1. Consolidated area (dark grey): high proportion of renovated houses, low vacancy rates, balanced social structure;

2. Area undergoing consolidation (medium grey);

3. Non-consolidated area (light grey): high demand for urban restructuring, high vacancy rates, social segregation. 


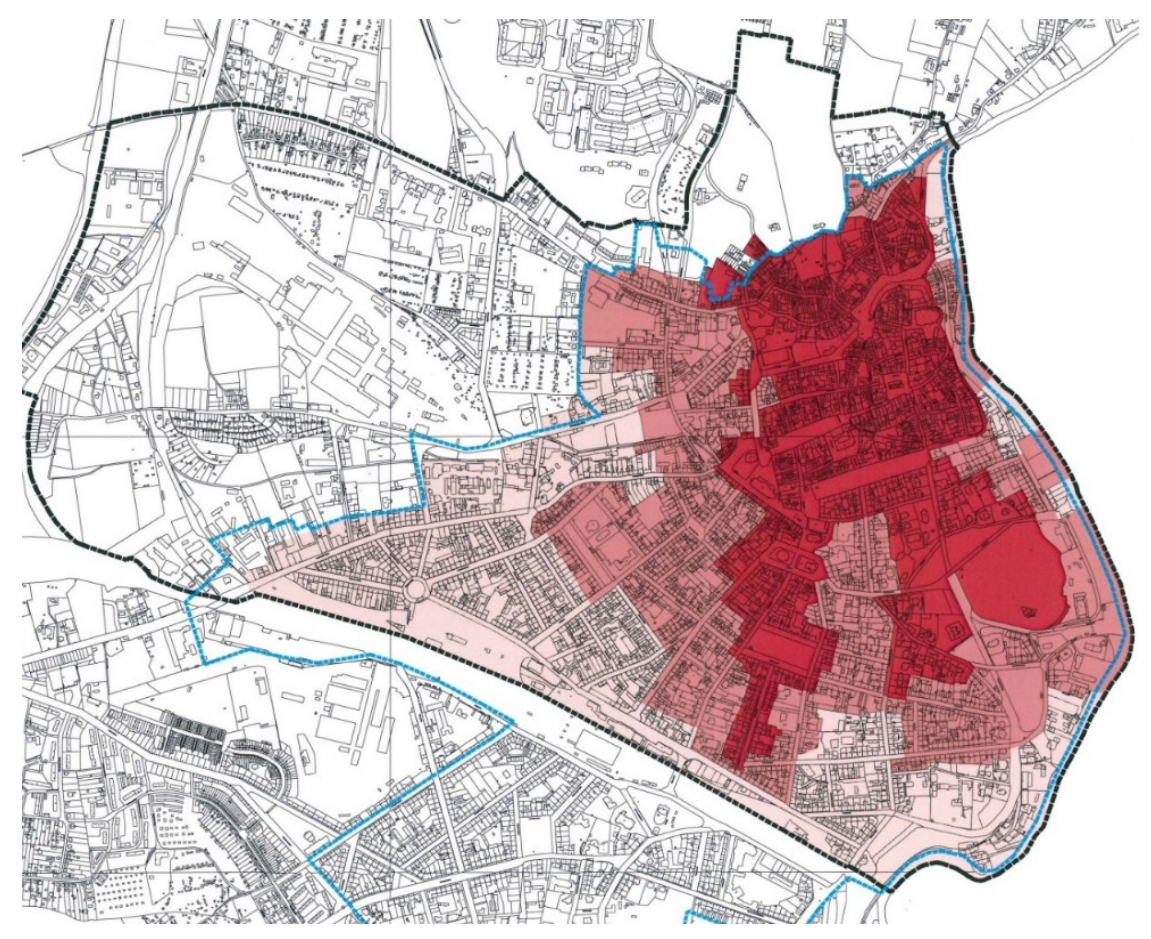

Figure 3. Three zones of urban consolidation-dark red: consolidated area, medium red: area undergoing consolidation, light red: non-consolidated area. Reprinted with permission from ref. [23].

The Matrix now intersects the specification of a single building in the four aspects (building typology, urban design evaluation, assessment of the planned project, forecast of urban impact) with the respective degree of consolidation of the specific zone, or specification in the other aspects. In each case, the most "sensitive" sub-evaluation is decisive for the result. In accordance with the Matrix, the less consolidated the area under consideration, the more structural interventions are imaginable for a building under monumental protection (see Figure 4).

The Matrix generates twelve categories of potential structural intervention in listed buildings, whereby the aim of the Matrix is the long-term preservation rather than the demolition of the historic building stock (see Figure 5). 


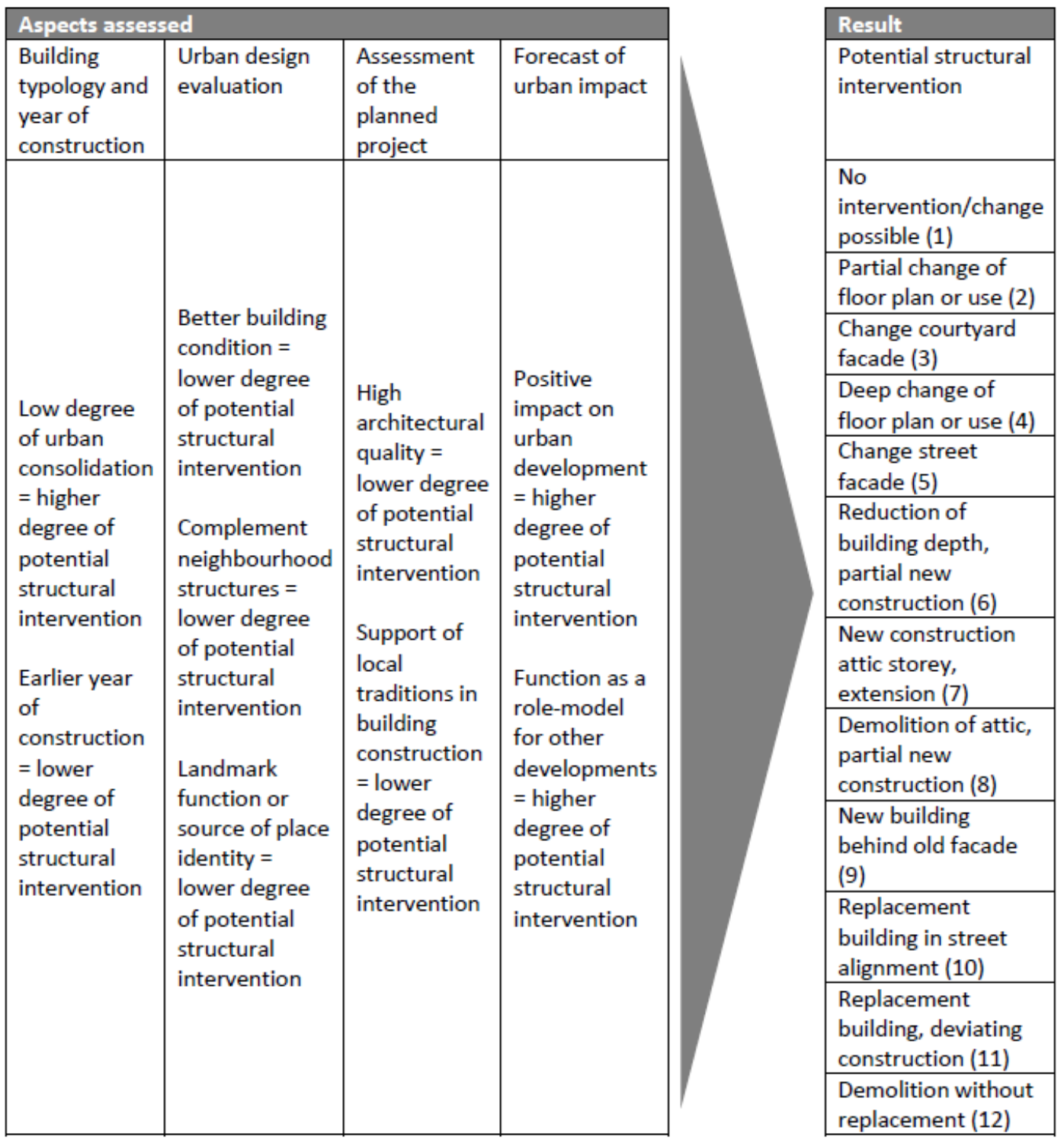

Figure 4. Simplified evaluation procedure of the Matrix. 

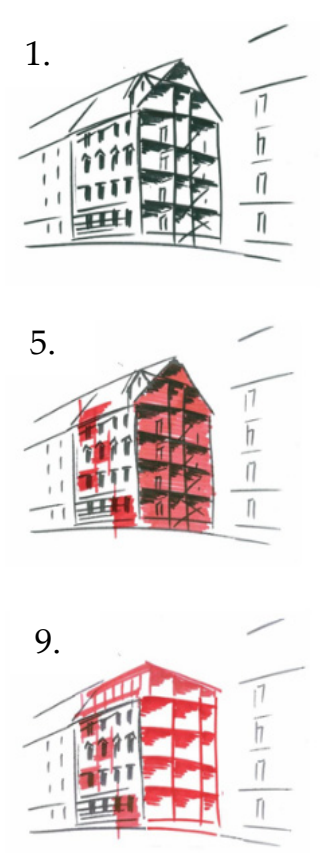
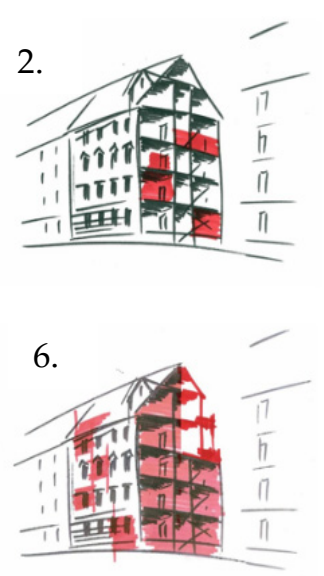

10.

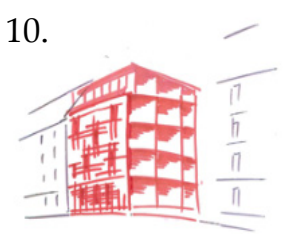

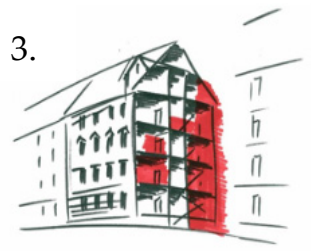
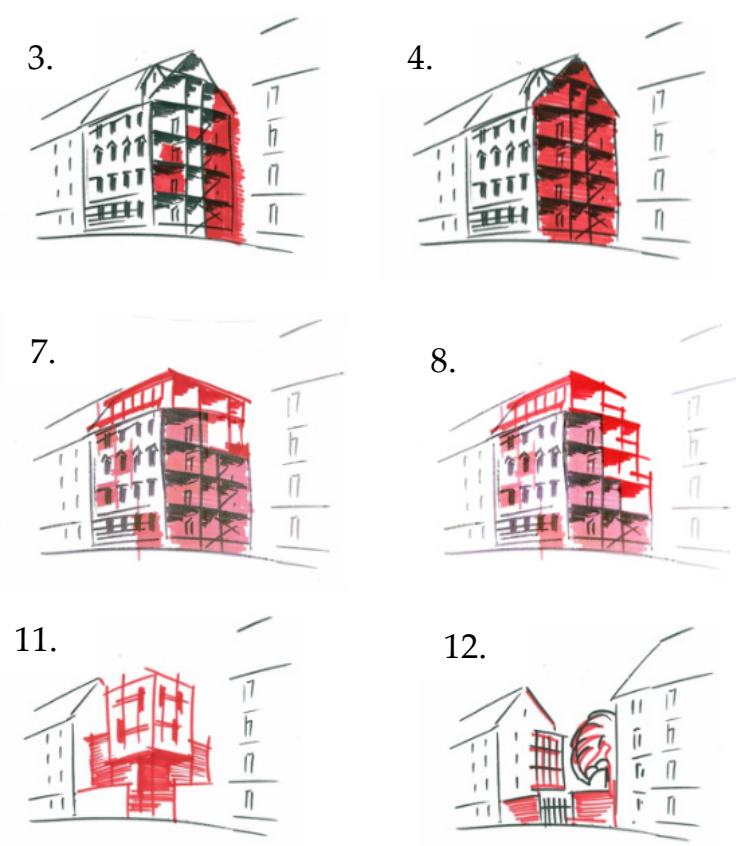

Figure 5. The 12 categories of structural intervention. Reprinted with permission from ref. [23].

\subsection{Application}

From the beginning, the 'Urban Transformation Matrix' was subject to heated discussions. The conservation of Görlitz's urban heritage is a topic of public debate, reflected by numerous professional measures to protect the urban fabric as well as voluntary activities and initiatives. Many of those involved in such initiatives were sceptical of the Matrix, fearing increased demolition activities or massive interventions in listed buildings that would damage the city's unique historic centre. There were fewer conflicts within the municipal authority itself because public officials for heritage preservation were also responsible for urban development. However, the authority responsible for heritage preservation at the state level feared a weakening of heritage preservation. While understanding the unique case of Görlitz, it did not want the Matrix approach to become a development model for other cities.

After intensive hearings, the agency agreed to an experimental phase of two years to test the 'Urban Transformation Matrix' and to evaluate the experiences that occurred during this period. Subsequently, a council resolution was passed to approve the application of the Matrix locally for a limited time period only. Meanwhile, the test period, which had been extended to three years, ended, so that conclusions could already be drawn.

\section{Experiences and Conclusions: Not Yet a Collaborative Tool}

The Urban Transformation Matrix is certainly an innovative instrument. A survey of approaches aimed at tackling the conflict between revitalisation and heritage preservation in Germany has confirmed that no other model is comparable to this tool in approach or complexity.

\subsection{Experiences with the Application of the Urban Transformation Matrix}

In general, the municipality of Görlitz was and is rather cautious about implementing the Urban Transformation Matrix. Indeed, the tool is not well-known among architects, planners or investors, and the city is doing little to raise awareness of it. Due to the limited resources of the municipal authority, a comprehensive application of the Matrix is unrealistic. Therefore, the Matrix can only be applied in selected cases. The aim of the Matrix is to discuss the possibilities of revitalising listed but vacant buildings as early and 
as openly as possible, accepting certain structural interventions. To this end, dissemination of information among professionals and potential investors is crucial.

At the end of the test phase and on the basis of the positive experience gained, the city council has continued to allow the municipal urban development authority to continue using the Matrix as a testing tool. The number of buildings in danger of collapsing in Görlitz is increasing. More and more often, the question arises as to what should be done with buildings whose restoration would not be in line with market conditions. At the same time, there would be a need for living space that could not be produced in the affected building. In case of doubt, the Matrix serves here as a decision support tool. A prerequisite for this is, of course, that the house owner and the heritage preservation authorities are willing to talk and collaboratively search for solutions.

Another function of the Matrix, which was not intended at first, is to draw attention to municipal problems at the federal and state levels. Ultimately, the Matrix is a non-binding instrument that must be flanked by more-binding instruments. Here, the Matrix is seen as a preliminary stage for bringing about legal changes (heritage protection act) [24].

Furthermore, the Matrix is used as an evaluation tool when deciding on municipal measures to secure buildings. In the case of acutely collapsing buildings, and if the owners are unwilling or unable to do so, the city feels obliged to take measures to ensure safety and prevent danger. These range from public safety measures from the installation of safety nets to protect against falling plaster and bricks to the installation of emergency roofs for buildings that are particularly worthy of preservation. These measures and the associated costs are certainly controversial. The Urban Transformation Matrix serves to evaluate and justify such measures.

\subsection{Conclusions}

The Matrix is a tool that specifically reflects the situation in Görlitz, where the urban centre has a high proportion of vacant, mostly listed, historic buildings. As described above, action is urgently required in Görlitz due to the critical condition of many vacant buildings as well as the current (and potentially temporary) interest of investors in smaller towns beyond the metropolitan hubs. The Matrix approach is possibly transferable to other small- and medium-sized cities in peripheral locations, which face similar challenges as Görlitz. Further research is required to determine how far and under which circumstances the Matrix approach can be transferred to other contexts or extended to include additional aspects (e.g., energy efficiency).

Currently, one cannot say with any degree of certainty whether the Matrix is a generally applicable tool for assessing structural interventions in the building stock that accord with preservation orders. The same applies to the question of whether the Matrix contributes to a reduction in the vacancy rate and, thus, to the revitalisation and upgrading of urban districts.

Until now, local residents as well as the Saxon authorities have shown great concern for the preservation of monuments in Görlitz. This concern, along with a lack of support for the Matrix approach at both the local and state levels, has fostered uncertainty within the municipality. Such uncertainty might be the reason why the local authority has only cautiously promoted the Matrix among architects, planners, developers and investors within the city and beyond.

The Urban Transformation Matrix is a communicative tool accompanying the formal approval process for building permissions. Clearly, promotion and communication activities are crucial to developing urban areas while preserving the historic fabric. Since Görlitz is well known internationally as a film location, promotion of the Matrix should also focus on an international audience.

Finally, it is important to point out that the Matrix is not a product of academic or consultancy work but has been elaborated by the municipal urban development authority, which is responsible for both heritage preservation and urban development. Although municipal staffing levels in shrinking cities are under pressure, innovation can be achieved 
in the public sector at the local level. Now the municipality of Görlitz has to gain a certain level of self-confidence to better promote and communicate the Matrix approach. Scientific support and monitoring can help disseminate the approach among academics and expert groups.

Author Contributions: Conceptualization, R.K.; Formal analysis, C.Z.; Investigation, C.Z.; Methodology, R.K.; Project administration, R.K.; Writing-original draft, R.K. and C.Z. Both authors have read and agreed to the published version of the manuscript.

Funding: This research received no external funding.

Institutional Review Board Statement: Not applicable.

Informed Consent Statement: Not applicable.

Data Availability Statement: Not applicable.

Conflicts of Interest: The authors declare no conflict of interest.

\section{References}

1. European Commission. Eurostat 2017: Urban Europe-Statistics on Cities, Towns and Suburbs—Executive Summary. Available online: http:/ / ec.europa.eu/eurostat/documents/3217494/7596823/KS-01-16-691-EN-N.pdf (accessed on 11 January 2018).

2. Fol, S.; Cunningham-Sabot, E. « Déclin urbain » et Shrinking Cities: Une évaluation critique des approches de la décroissance urbaine. Ann. de Géographie 2010, 674, 359-383. [CrossRef]

3. Panagopoulos, T.; Guimarães, M.H.; Barreira, A.P. Influences on citizens' policy preferences for shrinking cities: A case study of four Portuguese cities. Reg. Stud. Reg. Sci. 2015, 2, 141-170. [CrossRef]

4. Wolff, M.; Wiechmann, T. Urban growth and decline: Europe's shrinking cities in a comparative perspective 1990-2010. Eur. Urban Reg. Stud. 2018, 25, 122-139. [CrossRef]

5. Kühn, M. Peripheralization: Theoretical Concepts Explaining Socio-Spatial Inequalities. Eur. Plan. Stud. 2015, 23, 367-378. [CrossRef]

6. Danielewicz, J. The Sustainable Development Idea in the Management of European Metropolitan Areas. Econ. Environ. Stud. 2017, 17, 279-296. [CrossRef]

7. Zevi, A.T. The Century of Global Cities: How Urbanisation Is Changing the World and Shaping our Future; Ledizioni LediPublishing: Milan, Italy, 2019.

8. Burayidi, M.A. (Ed.) Downtowns: Revitalizing the Centers of Small Urban Communities; Routledge: New York, NY, USA, 2001.

9. Brabazon, T. Unique Urbanity? Rethinking Third Tier Cities, Degeneration, Regeneration and Mobilit; Springer: Singapore, 2015.

10. Murphy, E.; Redmond, D. The role of 'hard' and 'soft' factors for accommodating creative knowledge: Insights from Dublin's 'creative class'. Ir. Geogr. 2009, 42, 69-84. [CrossRef]

11. Rodríguez-Pose, A.; Ketterer, T.D. Do Local Amenities Affect the Appeal of Regions in Europe for Migrants? J. Reg. Sci. 2012, 52, 535-561. [CrossRef]

12. Buch, T.; Hamann, S.; Niebuhr, A.; Rossen, A. What Makes Cities Attractive? The Determinants of Urban Labour Migration in Germany. Urban Stud. 2013, 51, 1960-1978. [CrossRef]

13. Tweed, C.; Sutherland, M. Built cultural heritage and sustainable urban development. Landsc. Urban Plan. 2007, 83, 62-69. [CrossRef]

14. Hełpa-Liszowska, K. Dziedzictwo kulturowe jako czynnik rozwoju lokalnego. Studia Oeconomica Posnaniensia $2013,1,5-18$.

15. Battis-Schinker, E.; Knippschild, R. Baukultur im Grenzraum von Deutschland und Polen. Forschungsansatz zur Messung von Lebensqualität in Historischen Klein- und Mittelstädten [Building Culture in the Border Region of Germany and Poland. Research Approach to Measuring Quality of Life in Historic Small and Medium-Sized Towns]; Kulturgüterschutz Forum 34/2020; Bundesamt für Bevölkerungsschutz: Bern, Switzerland, 2020; pp. 37-44.

16. Ferretti, V.; Bottero, M.; Mondini, G. Decision making and cultural heritage: An application of the Multi-Attribute Value Theory for the reuse of historical buildings. J. Cult. Herit. 2014, 15, 644-655. [CrossRef]

17. Blundo, D.S.; Ferrari, A.M.; Pini, M.; Riccardi, M.P.; García, J.F.; Del Hoyo, A.P.F. The life cycle approach as an innovative methodology for the recovery and restoration of cultural heritage. J. Cult. Herit. Manag. Sustain. Dev. 2014, 4, 133-148. [CrossRef]

18. Albrechts, L. Strategic (Spatial) Planning Reexamined. Environ. Plan. B Plan. Des. 2004, 31, 743-758. [CrossRef]

19. Stadt Görlitz, Stadtplanungs- und Bauordnungsamt (2009): Große Kreisstadt Görlitz. Integriertes Stadtentwicklungskonzept INSEK. Demographie, Fachkonzepte Städtebau und Denkmalschutz, Wohnen. Fortschreibung 2009/2010. [Large district town Görlitz. Integrated Urban Development Concept INSEK. Demography, Specialist Concepts for Urban Development and Monument Conservation, Housing. Update 2009/2010.] Görlitz. Available online: https:/ / www.goerlitz.de/Stadtentwicklungskonzept.html (accessed on 31 March 2021).

20. City of Görlitz. Official Website-Historic City. 2020. Available online: https://www.visit-goerlitz.com/Denkmal_Goerlitz.html (accessed on 17 June 2020). 
21. Ryberg-Webster, S.; Kinahan, K.L. Historic preservation in declining city neighbourhoods: Analysing rehabilitation tax credit investments in six US cities. Urban Stud. 2016, 54, 1673-1691. [CrossRef]

22. Federal Foundation of Baukultur. Baukultur Report 2016/17; City and Village: Potsdam, Germany, 2016.

23. Menzel, W. Stadt Görlitz, Amt für Stadtentwicklung: Görlitzer Modell: Stadtumbau-Matrix. Bewertungssystem zur Weiterentwicklung innerstädtischer Bausubstanz [The Görlitz Model: Urban Transformation Matrix. An evaluation system for developing the inner-city building stock]. Unpublished presentation as draft resolution for the city council of the city of Görlitz, 4 May 2016.

24. Wilke, H. Die Görlitzer Stadtumbau-Matrix [The Görlitz Urban Transformation Matrix]. Sachs.-Kur. 2019, 1, 12-15. 